\title{
Analysis of Load Flow Method With Static Var Compensator (SVC) for Minimizing Transmission Losses in Power System : A Case Study of 500 KV Java-Bali Electrical Power System
}

\author{
$1^{\text {st }}$ Chico Hermanu Brillianto Apribowo \\ Department Electrical Engineering \\ Faculty of Engineering \\ Universitas Sebelas Maret \\ Surakarta, Indonesia \\ chico@ft.uns.ac.id
}

\author{
$2^{\text {nd }}$ Oktavian Listiyanto \\ Department Electrical Engineering \\ Faculty of Engineering \\ Universitas Sebelas Maret \\ Surakarta, Indonesia \\ 29.oktavian@gmail.com
}

\begin{abstract}
Demand for electricity is increasing rapidly, the consequence of this is a threat to the stability of the electrical system, one of which is the voltage stability. FACTS or Flexible Alternating Current Transmission System is electronic equipment that is able to regulate electric power transmission that can be used to overcome stability problems. This research will analyze the use of Static Var Compensator (SVC) as one of the equipment from FACTS to overcome the stability of the most critical buses by using the $500 \mathrm{kV}$ Java-Bali electricity system using PSAT. Results from using the power flow method in the $500 \mathrm{kV}$ Java-Bali case show that the total active power generation is 12.144 p.u. and the total reactive power generation is 5.268 p.u. This value is obtained from the total addition of active power generation and reactive power of all plants in the $500 \mathrm{kV}$ Java-Bali system. While the total active power load is worth 12.058 p.u. and the total reactive power load is 4.65 p.u. This value is obtained from the total load on each bus plus the total losses incurred on the line.
\end{abstract}

Keywords-PF, SVC, FACTS.

\section{INTRODUCTION}

Developments in the current era of globalization create various increases in electricity demand both in industry and in households. Increasing electricity demand that continues to increase from time to time requires the plant to be able to operate up to the maximum limit set [1].

In actual circumstances, the Java-Bali transmission line system in 2013 had approached the maximum work operation (70-80\%) [2]. This is due to the very fast growth of load in Java-Bali by 7\% in 2013 and will increase again each year. Because of the increase in population and economy, the need arises to increase the capacity, flexibility, reliability, and security of the power transmission system. Due to everchanging market conditions, electric utilities are looking for different ways to efficiently utilize the old transmission lines to the maximum point of operation. But the consequences are the threat of voltage stability.

Maintaining voltage stability is very important to keep the system from collapsing stress [3]. The instability of the voltage causes the coupling system voltage to cause a decrease in the system voltage. One way to reduce the load on the system, increase the capacity of the transmission line, and improve system stability is to install FACTS [4]. FACTS or also called Flexible Alternating Current Transmission System is an electronic component that can reduce losses and increase capacitance in the transmission line.
The FACTS controller can significantly improve the load power margin of the power system [4]. The types of FACTS equipment are SVC, STATCOM, TCSC, SSSC, and UPFC. Benefits or savings obtained by installing FACTS can compensate costs at a reasonable time. SVC is used because it can regulate voltage and stabilize the transmission system.

In this study, the SVC placement in the $500 \mathrm{kV}$ Java-Bali electrical system will be simulated using PSAT. The experiment was carried out by performing a power flow simulation using PSAT to be able to see the results of the total generation, total load, and total losses generated in the $500 \mathrm{kV}$ Java-Bali electrical system.

\section{COMPONENT MODELLING}

\section{A. FACTS}

FACTS is a concept based on electronic-power controllers, which increases the value of the transmission network by increasing the capacity utilization of the device. Because this controller operates very fast, FACTS increases the safe operating limits of the transmission system without the risk of stability. The era of FACTS was triggered by the development of new solid-state electrical switching devices. Gradually, the use of FACTS has given birth to a new system that can be controlled.

The increase in load on the transmission network can sometimes cause the voltage in the network to collapse due to lack of reactive power sent to the load center. This is caused by an increase in reactive power consumption in the transmission network and its load characteristics. This resulted in problems in improving the economy and security of the operation of the network system. The above problems can be handled if you can adjust the operating margins when the power transmission can be adjusted. The operating margins can be handled substantially with rapid dynamic control of active and reactive power by control of power electronics at high voltages. The FACTS controller can be defined as power electronics based on the system and other static equipment used to control one or more parameters in an $\mathrm{AC}$ transmission system.

FACTS controllers are based on converter voltage sources, which include SVC, STATCOM, TCSC, SSSC, and UPFC. With developments in the field of power electronics, compensation on the transmission line can be realized so that electricity providers can control the flow of power, power losses in the electric power system, maintain voltage limits 
until they can meet the needs of increased loads with existing generation capabilities [5].

The technology developed at this time, which uses the concept of power electronics is FACTS. FACTS was initially used for control of generators, namely for voltage regulation, which works together with tap-changing and phase-shifting transformers. The reactor is also used to reduce the level of power flow and short circuit in the transmission net. And vice versa, the series capacitors are used to shorten the length of the channel and increase the flow of power capacitive series to compensate to prevent excessive voltage on the transmission line and increase the capacity of the system.

FACTS devices utilize the thyristor application for power electronics by utilizing power electronics control, FACTS is the first choice for compensation as well as control. FACTS can utilize the transmission line at thermal loading limits without worrying about the possibility of overload or overload. This situation is very important to increase the capacity of power distribution without increasing the number of transmission lines.

\section{B. $S V C$}

SVC is a static var generator that is connected to a shunt whose output adjusts to change to capacitive or inductive so that it can maintain or control certain parameters of each electric power [6]. SVC is one of the FACTS equipment that can be used to regulate voltage and stabilize the transmission system.

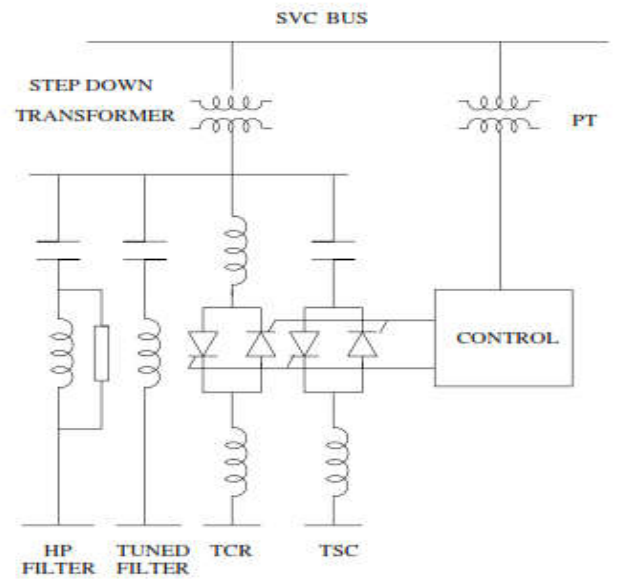

Fig. 1. SVC series [7]

SVC is the first FACTS controller equipment in the application of transmission systems, SVC is used to correct voltage on the network. In Figure 1, if the reactive load on the system is capacitive (leading), the SVC will use a thyristor controlled reactor to consume var from the system and reduce the voltage on the system. If the condition is inductive (lagging), then the bank capacitors will automatically turn on and will increase the voltage on the system. By connecting a thyristor-controlled reactor, which is a continuous variable, together with the installation of bank capacitors, the end result of a continuous or lagging power variable is found on the system.

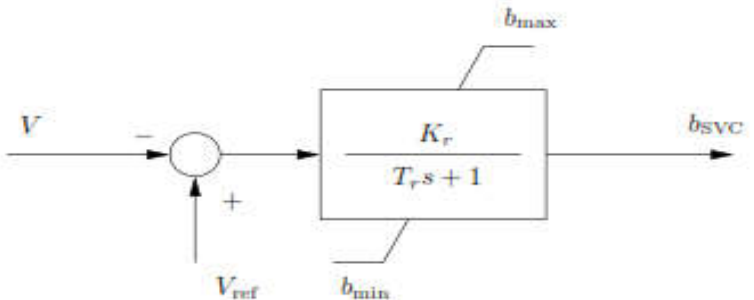

Fig 2. SVC Flow Diagram [8]

Figure 2 is an SVC that uses a constant regulator. In this model, the total of $B_{S V C}$ reactance is assumed and followed by the following differential equation:

$B_{\text {SVC }}=\left(K_{r}\left(V_{\text {ref }}-\mathrm{V}\right)-B_{\text {sVC }}\right) / T_{r}$

Then from the equation, it is solved again with an algebraic equation that expresses the reactive power injected by SVC:

$\mathrm{Q}=-B_{S V C} V^{2}$

\section{IMPLEMENTATION OF PROPOSED METHOD}

1. Take data including buses, generators, loads Java-Bali $500 \mathrm{kV}$ transmission systems.

2. Perform load flow simulations using PSAT on JavaBali $500 \mathrm{kV}$ transmission systems.

3. Analyze data obtained from load flow on Java-Bali 500 $\mathrm{kV}$ transmission systems.

\section{SIMULATION RESULT AND ANALYSIS}

Load flow or known as power flow is a very important method in the analysis of electric power systems. Load flow method is carried out to determine the steady-state characteristics. From this, it can be observed the initial stress profile and initial losses in a system. Following are the results of the simulation of the load flow method in the JavaBali $500 \mathrm{kV}$ case.

The simulation uses the Java-Bali $500 \mathrm{kV}$ system using PSAT version 2.1.10 in MATLAB 2016b.

\section{A. Base Case}

The initial step to see a picture of the state of the electric power system, in general, is to conduct a power flow simulation to see the voltage, total generation, total load, and losses.

Good or bad quality of distribution of the electric power system can be observed from the value of the voltage profile. Figure 3 shows that the voltage values from bus 1 to bus 25 are good. But bus 8 and bus 11 have the smallest voltage values. 


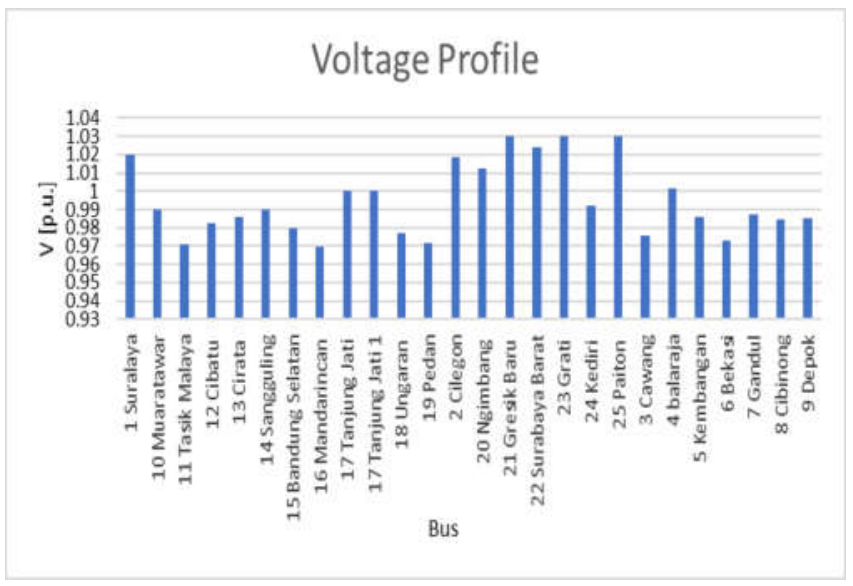

Fig 3. Voltage Profile Load Flow Jawa-Bali 500 kV

$$
\begin{aligned}
& \text { TABLE I TOTAL LOAD GENERATION AND LOSSES ON JAVA-BALI } \\
& 500 \mathrm{KV}
\end{aligned}
$$

\begin{tabular}{|c|c|}
\hline Total Generation & 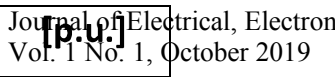 \\
\hline Active Power & 12.144 \\
\hline Reactive Power & 5.268 \\
\hline Total Load & [p.u.] \\
\hline Active Power & 12.058 \\
\hline Reactive Power & 4.65 \\
\hline Losses & [p.u.] \\
\hline Active Power & 0.086 \\
\hline Reactive Power & 0.618 \\
\hline
\end{tabular}

The simulation using the power flow method can be seen in the form of total generation, load, and losses in the system. For the results of using the power flow method in the JavaBali $500 \mathrm{kV}$ case can be seen in table 1 . From table 1 above shows that the total active power generation is 12.144 p.u. and the total reactive power generation is 5.268 p.u. This value is obtained from the total addition of active power generation and reactive power of all plants in the $500 \mathrm{kV}$ Java system. While the total active power load is worth 12.058 p.u. and the total reactive power load is 4.65 p.u. This value is obtained from the total load on each bus plus the total losses that occur on the channel. Losses occur because of the value of the channel impedance, so the generator must supply more power to meet the total load requirements that exist. The greater the impedance the greater the channel losses, and vice versa. The value of channel losses or losses will also result in a system voltage drop which results in the voltage at the end of the line being smaller than the value that should be.

\section{B. $S V C$}

The SVC placement on Bus Pedan which has the lowest and most critical profile stress is based on the results of the $\mathrm{CPF}$ simulation in the form of a PV curve and the voltage profile. SVC on Pedan Bus which has the lowest profile voltage and is the most critical compared to other buses. The results of the SVC installation on Bus Pedan can be seen in Figure 4 and Table 2.

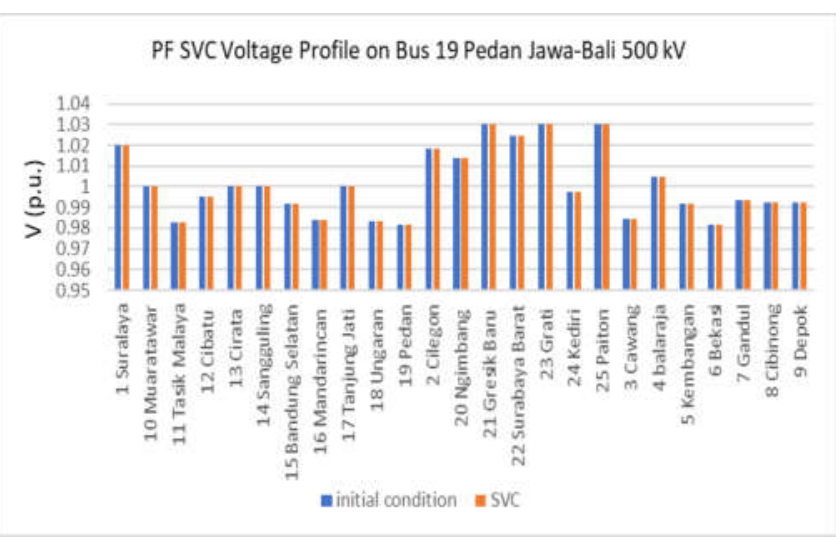

Fig 4. PF SVC Voltage Profile on Bus 19 Pedan on JavaBali $500 \mathrm{kV}$

TABLE 2 TOTAL LOAD GENERATION AND LOSSES ON JAVA-BALI Information, and Communication Technology (JEEICT)

\begin{tabular}{|c|c|}
\hline Total Generation & [p.u.] \\
\hline Active Power & 12.144 \\
\hline Reactive Power & 5.268 \\
\hline Total Load & [p.u.] \\
\hline Active Power & 12.058 \\
\hline Reactive Power & 4.65 \\
\hline Losses & [p.u.] \\
\hline Active Power & 0.086 \\
\hline Reactive Power & 0.618 \\
\hline
\end{tabular}

The total results of generation, load, and losses from SVC on Bus Pedan can be seen in Table 1 compared to table 2. The installation of SVC did not reduce or increase losses on the line.

\section{CONCLUSION}

After testing the power flow in the $500 \mathrm{kV}$ Java-Bali electricity system to compare it to when the power flow was performed when the SVC was installed in the $500 \mathrm{kV}$ JavaBali electrical system it was found that there was no increase in the total generation, and the total load, so that losses which are obtained when doing power flow is the same when not installing it when installing SVC on the system.

\section{REFERENCES}

[1] A. Gupta and P. Sharma, "Optimal Placement of FACTS Devices for Voltage Stability Using Line Indicators," IEEE Fifth Power India Conference, 2012.

[2] "Rencana Usaha Penyediaan Tenaga Listrik," PT PLN (Persero), 2013.

[3] M. Nizam, A. Mohamed and A. Hussain, "An 
Adaptive Undervoltage Load Shedding Againts Voltage Collapse Based Power Transfer Stability Index," Journal of Electrical Engineering \& Technology, vol. 2, pp. 420-427, 2007.

[4] M. A. Kamarposhti, M. Alinezhad, H. Lesani and N. Talebi, "Comparison of SVC, STATCOM, TCSC, and UPFC Controllers for Static Voltage Stability

[5] Evaluated by Continuation Power Flow Method," IEEE Electrical Power \& Energy Conference, 2008.

N. G. Hingorani and L. Gyugyi, Understanding FACTS: Concepts and Technology of Flexible AC Transmission Systems, New York: IEEE Press, 2000.
[6] R. Kumari and Parveen, "Brief Study on TSCS, SSSC, SVC FACTS Device," International Journal of Advanced Research in Electrical, Electronics and Instrumentation Engineering, 2016.

[7] K. R. Padiyar, FACTS Controllers in Power Transmission and Distribution, New Age International Publishers, 2007.

[8] F. Milano, Power System Analysis Toolbox Version 2.1.8, Software and Documentation, 2005.

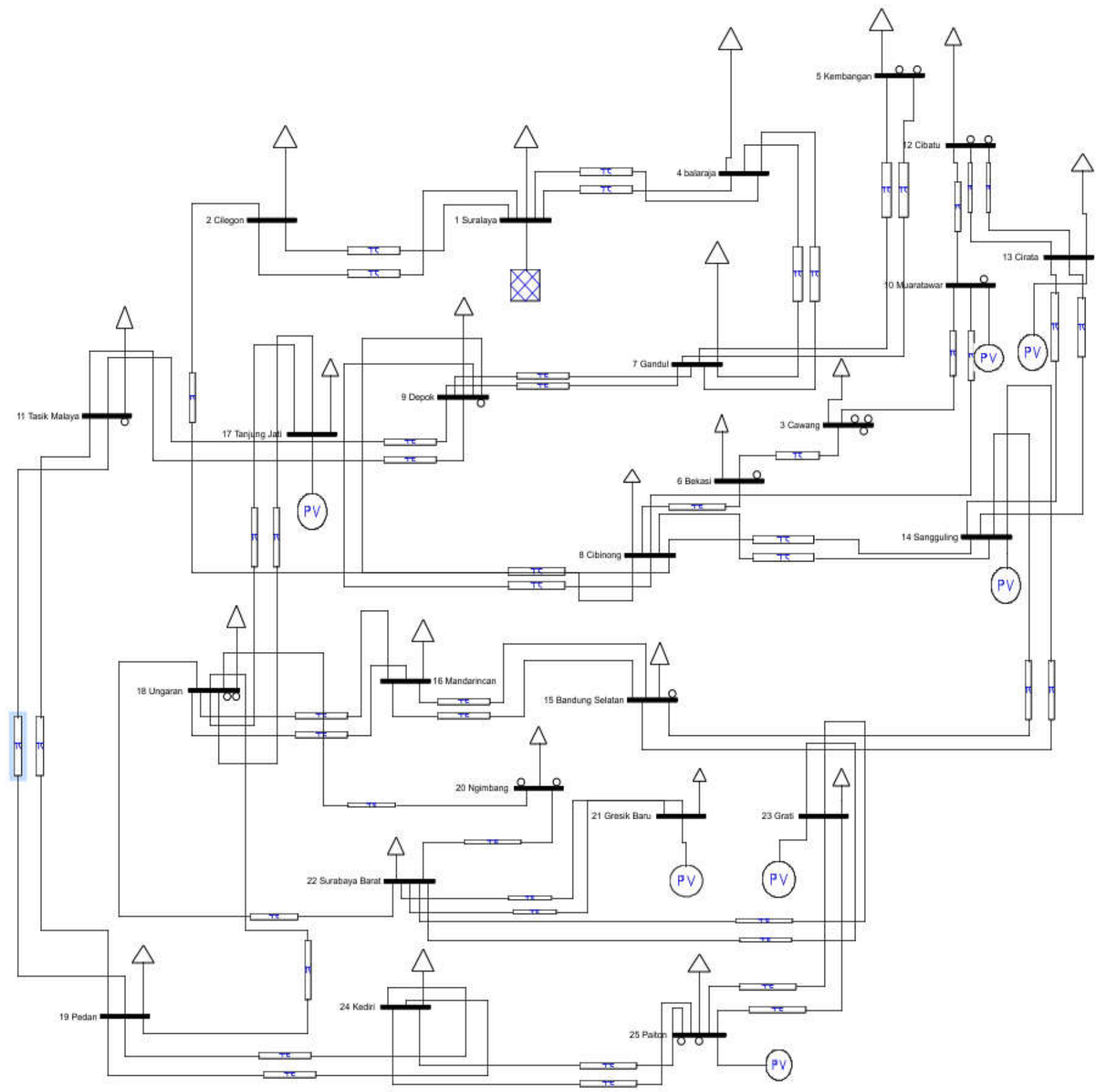

Fig. 5 Java-Bali 500 kV Single Line Diagram 